\title{
66 Infants with Urinary Tract Infection in First Month of Life
}

\author{
J. M. LITTLEWOOD \\ From Seacroft Hospital, Leeds
}

\begin{abstract}
Littlewood, J. M. (1972). Archives of Disease in Childhood, 47, 218. 66 infants with urinary tract infection in first month of life. Sixty-six newborn infants with urinary tract infection are described. The wide variation in clinical manifestations is stressed and suggested as an explanation for the variety of clinical descriptions, incidence, and prognosis noted by previous authors. The condition commonly presents on the sixth or seventh day, there is no seasonal incidence, boys are affected more frequently than girls. There was a correlation with maternal infection, perinatal anoxia, and birthweight either below or above the normal range. Unsatisfactory weight progress, lethargy, and anorexia were the most frequent clinical signs. The overall mortality was $11 \%$ and further infection occurred in $37 \%$ of girls and in $10 \%$ of the boys. A clinical classification for the condition is suggested.
\end{abstract}

Though urinary tract infection is a relatively common occurrence in the first month of life (Craig, 1935; James, 1959; Lincoln and Winberg, 1964; O'Doherty, 1968; Littlewood, Kite, and Kite, 1969), there are few large series of such infants reported. Previous publications reveal a lack of general agreement as to the usual clinical picture to be expected, which is probably due to the fact that some authors are reporting infants clinically ill with urinary infection, together with other infants who have been detected when the condition is causing little clinical disturbance.

In this paper a large series of infants with clinical illness attributed to urinary infection is reviewed. 59 infants were diagnosed as a result of investigation of their illness and 7 were detected during the course of a screening survey while relatively asymptomatic. 50 of the infants were examined personally by the author during the course of their initial illness and in addition to usual laboratory investigations, microscopy of a fresh specimen of uncentrifuged urine was carried out as further confirmation of the diagnosis.

The term 'urinary tract infection' is used in preference to 'pyelonephritis', though renal parenchymal infection is certainly present in some of these infants, in others the differentiation between upper and lower urinary tract infection is not possible either by clinical or laboratory methods.

Received 6 October 1971.

\section{Methods}

The diagnosis of urinary tract infection was usually clear cut where urine was examined in the symptomatic infants, but quantitative cultures and urine white cell counts were performed only on later infants in the series. In earlier case, gross bacteriuria and pyuria were usually evident on microscopy and a heavy growth of the responsible organism obtained on culture. The diagnosis in 2 of the 7 asymptomatic infants was confirmed by suprapubic aspiration where the findings of voided urine were equivocal.

\section{Mothers}

Maternal infection. $45 \%$ of the mothers of infected infants were known to have had some type of infection or pyrexia during labour or in puerperium.

Puerperal pyrexia. This $\left(37.8{ }^{\circ} \mathrm{C}\right)$ occurred in $30 \%(18 / 60)$ of mothers whose infants were infected. In a control group of mothers only $10.5 \%(7 / 76)$ had puerperal pyrexia. This difference is significant $(0.02>\mathrm{P}>0.01)$.

Maternal urinary tract infection. 9\% $(6 / 66)$ of the mothers of infected infants had clinical evidence of symptomatic urinary infection, compared with $4.5 \%$ of a control series whose infants were known to be uninfected. Though this difference is not significant $(0.5<\mathrm{P}<0.3)$, both these figures relate to symptomatic pyelonephritis of pregnancy rather than asymptomatic bacteriuria. Subsequent cases (not included in this series) suggest that the incidence of maternal 
urinary infection, whether symptomatic or asymptomatic, will not be significantly higher than in a control group.

Duration of ruptured membranes before delivery. There was no significant difference between the interval following rupture of the membranes and birth of the infant, when infected infants were compared with a control series of infants proved to be uninfected.

Mode of delivery. In $39 \%(26 / 66)$ of the infected infants there was a history of delivery other than spontaneously by the vertex, in contrast to $7 \%(205 /$ 2827) of a representative hospital population of newborns. Breech delivery and caesarean section were significantly more frequent in the infected groups $(\mathrm{P}<0.01)$

\section{Infants}

Annual incidence. There has been a significant increase in the number of affected infants in the maternity hospital observed in the years 1965,1966 , and 1967 and compared with earlier years (Fig. 1). Probably

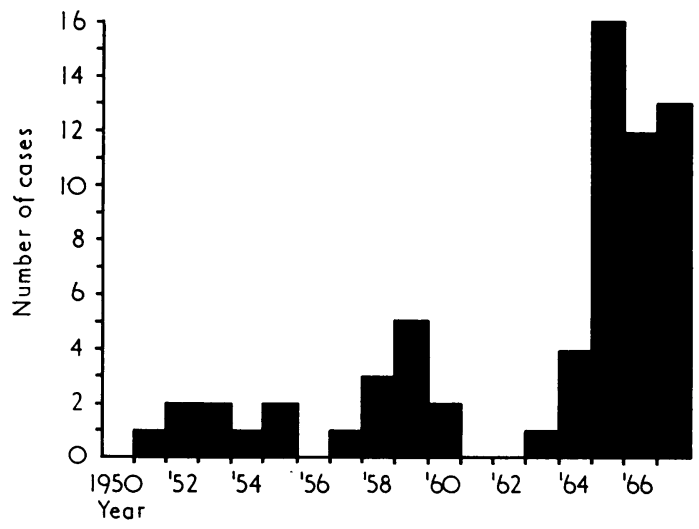

FIG. 1.-Incidence of urinary infection by years.

this increase in observed cases has been an increased detection rate, for it correlates with the development of a special interest in the condition in 1964.

Seasonal incidence. In the present series there is no seasonal variation in incidence. This contrasts with the increase in incidence in winter noted in older children with urinary tract infection (Wharton, Gray, and Guild, 1937; Burke, 1961 ; Smellie et al., 1964; Stansfeld, 1966).

Birthweight. When the birthweights of 65 infected infants (birthweight unknown in one case) were compared with those of a representative hospital population of liveborn infants, it was apparent that the mean birthweight was higher in the infants with urinary infection of whom $43 \%(28 / 65)$ were $3630 \mathrm{~g}(8 \mathrm{lb})$ or more $(0.05>P>0.02)$. The excess proportion of large infants in the infected group is offset not by a deficiency of those less than $2720 \mathrm{~g}(6 \mathrm{lb})$ but by a deficiency in those of normal birthweight 2720 to $3600 \mathrm{~g}$.

Maturity. A gestation period of 38 weeks or less was recorded in $24 \%(16 / 66)$ of the infected infants and $17 \%(491 / 2827)$ of the control group; a maturity of 42 weeks or more was recorded in $21 \%(14 / 66)$ infected infants and $17 \%(492 / 2827)$ of the control group.

Perinatal anoxia. The presence of asphyxia or fetal distress was determined by inspection of the hospital records, and the infants were grouped into 1 of 4 broad categories of 'moderate asphyxia', 'severe asphyxia', 'fetal distress', and 'normal'.

In a control series of 592 uninfected newborns 15\% (133/592) had some degree of perinatal anoxia whereas $33 \%(22 / 66)$ of infected infants had been anoxic. 'Severe asphyxia' (Apgar 2 or below at 1 minute) occurred in only $1 \%(7 / 592)$ of the uninfected control infants but in no less than $9 \%(6 / 66)$ of infected infants $(P<0.01)$. This finding that a greater number of infected infants than controls have severe anoxia, suggests that the latter may predispose to the development of urinary infection in the newborn period (Table I).

TABLE I

Perinatal Anoxia in Infected Infants and a Control Series

\begin{tabular}{|c|c|c|c|c|}
\hline \multirow{2}{*}{ Anoxia } & \multicolumn{2}{|c|}{ Uninfected } & \multicolumn{2}{|c|}{ Infected } \\
\hline & No. & $\%$ & No. & $\%$ \\
\hline $\begin{array}{l}\text { Nil } \\
\text { Moderate } \\
\text { Severe } \\
\text { Fetal distress } \\
\text { Total }\end{array}$ & $\begin{array}{r}499 \\
67 \\
7 \\
19 \\
592\end{array}$ & $\begin{array}{r}84 \\
11 \\
1 \\
3 \\
99\end{array}$ & $\begin{array}{r}44 \\
12 \\
6 \\
4 \\
66\end{array}$ & $\begin{array}{r}67 \\
18 \\
9 \\
6 \\
100\end{array}$ \\
\hline
\end{tabular}

Comparison between the sexes for the presence of anoxia in the infected and uninfected infants is difficult as the sex distribution is very different in the 2 populations. In the uninfected control group the male : female ratio is $1.03: 1$, against $2 \cdot 3: 1$ in the infected infants. Among the anoxic of each group it is $1.5: 1$ in the uninfected, and 4.5:1 in the infected. Though there are twice as many males as females in the infected groups as in the uninfected population, there are 4 times the number of anoxic boys to girls in the infected as there are in the control population. The more frequent occurrence of anoxia in males is in keeping with the male : female ratio of $1 \cdot 3: 1$ for deaths from intrapartum anoxia (Butler and Bonham, 1963).

A large proportion of the infected males who also had positive blood cultures had been severely asphyxiated at birth. In the uninfected group the ratio of anoxic to normal was $14: 1$ (74/518); in those with positive blood cultures in the infected series the ratio of anoxic to normal was $5: 4$ (excluding one unknown). This difference is significant $(P<0.01)$. 
Age of onset of clinical signs. Clinical signs appeared most commonly between the 5 th and 8 th days of life.

Sex incidence. There is a significant preponderance of male infants in the present series, there being 46 boys and 20 girls (i.e. $70^{\prime \prime}$ o boys and $30^{\circ} \%$ girls)-a male : female ratio of $2 \cdot 3: 1(\mathrm{P} \cdot 0 \cdot 01)$.

Reasons for urine examination. These are summarized in Table II. The practice of daily temperature taking in all newborns has been found to be of general diagnostic value (Craig, 1963). In the present series the presence of pyrexia $(>37 \cdot 7 \mathrm{C})$ was the most frequent reason

TABLE II

Clinical Signs Leading to Urine Examination

\begin{tabular}{l|cc}
\hline \multicolumn{1}{c}{ Sign } & Number of Infants & Percentage \\
\hline Pyrexia & 18 & 27 \\
Unsatisfactory weight & 16 & 24 \\
Vomiting & 6 & 9 \\
General illness & 6 & 9 \\
'Cerebral' & 4 & 6 \\
Lethargy & 3 & 4 \\
Loose stools & 2 & 3 \\
Jaundice & 2 & 3 \\
Known anomaly & 2 & 3 \\
Urine recovery cases & 7 & 11 \\
& & \\
\hline
\end{tabular}

for urine examination in infants subsequently found to have symptomatic urinary tract infection. Abnormality of the urine or micturition observed by the nursing staff was never the main indication for the first urine examination.

Seven of the 8 infected infants detected during the screening survey (Littlewood et al., 1969) were detected before clinical disturbances had been observed-the other infant has been included in the 'unsatisfactory weight progress' group, as this was the indication for further urine examination on the 10th day following which the diagnosis was established-urine at 6 days had been uninfected.

Main signs and frequency of occurrence. The present series includes 66 infants with urinary infection of all grades of severity (Fig. 2).

Unsatisfactory weight progress $\left(95^{\prime \prime}{ }^{\prime}\right)$. This is almost constant; lethargy and anorexia are usually associated. The fact that weight is an objective measurement, and lethargy and anorexia more dependent upon individual observations may account for the more frequent incidence of failure to gain weight.

Pyrexia. Pyrexia ( $>37.5$ C rectally) as well as being the most frequent reason for requesting urine examination is a frequent sign in the series as a whole. However, the fact that $15^{\circ} \%$ of infants where urinary infection was causing other signs had no pyrexia at any time (despite 4-hourly temperature taking) is noteworthy. The classical high remittent pyrexia described by earlier

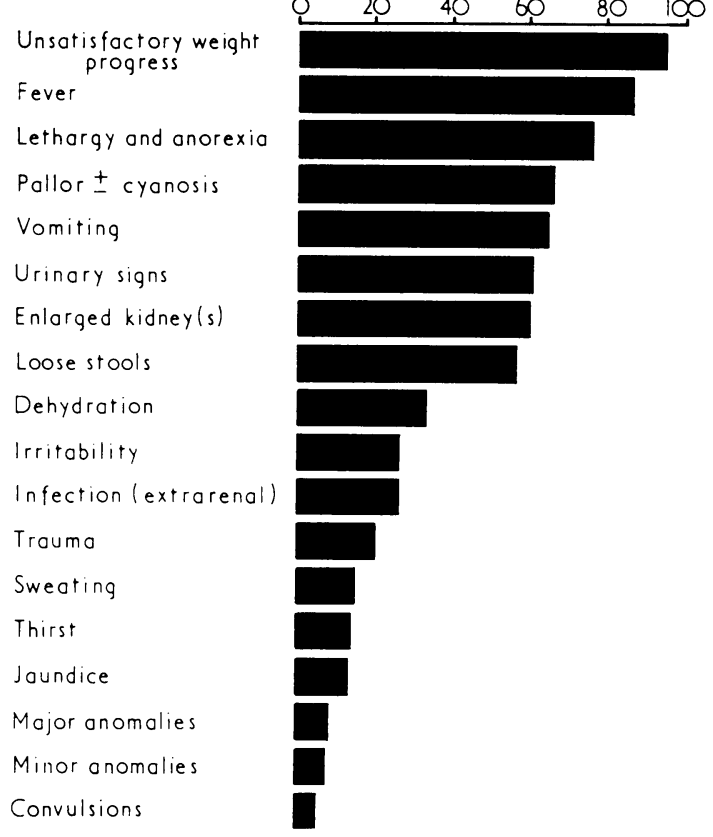

FIG. 2.-Frequency of signs in 66 infants.

writers was only occasionally observed; however, when effective chemotherapy is employed the infants are frequently apyrexial within 24 hours.

Hypothermia ( $35 \cdot 5$ C) was occasionally recorded in the severely ill infants.

Vomiting. Though occasionally the presenting sign of the condition, vomiting prompted urine examination in only 7 of 61 cases. The presence of even a single vomit has been recorded as 'vomiting' but despite this the incidence in this series $\left(66^{\prime \prime},\right)$ differs little from that found in a large series of normal infants (Craig, 1961).

Clinically observed signs relating to the urine were recorded in $55 \%$ of the series yet they were observed after the diagnosis had been established and in no instance was the first abnormality observed.

Readily palpable kidneys. The intepretation of the $\tilde{O}$ findings on kidney palpation in the newborn are $\underset{\omega}{\mathcal{O}}$ subject to much observer variation; in these infants $54^{\prime \prime}$. had palpable kidneys. and in some there was general agreement among a number of experienced observers that the kidneys were more readily palpable than normal. On more than one occasion so marked was the inflammatory swelling that hydronephrosis was suspected, yet when the infection was controlled the swelling settled and the kidneys were subsequently normal on pyelography. 
When marked enlargement occurred there was usually both severe systemic signs of general illness, and additional evidence of impaired renal function as evidenced by a severe degree of nitrogen retention.

In infants where both the blood urea and a definite opinion regarding the size of the kidneys were available, 16 of 20 infants $(80 \%)$ with a blood urea level of more than $60 \mathrm{mg} / 100 \mathrm{ml}$ had readily palpable kidneys, and only 4 of $10(40 \%)$ infants with urea of less than 60 mg had this sign.

It is surprising that this useful clinical sign is mentioned infrequently by earlier writers on this subject, even when large series of cases were reviewed. Davis and Chumley (1966) have recently emphasized this physical sign.

Diarrhoea. This has been noted to be a frequent accompaniment of urinary infection both in the newborn and older infants by many previous writers, and was present in $50 \%$ of our cases.

Dehydration (30\%), irritability (27\%), sweating, thirst, jaundice, convulsions (all less than $20 \%$ ) were relatively infrequent. This is probably a reflection both of early diagnosis before serious systemic disturbance had occurred and also of the institution of effective therapy with either sulphonamides or antibiotics with the avoidance of the protracted clinical course which occurred before chemotherapy was generally available.

Jaundice. Jaundice of some degree was reported in $11 \%$ of cases, while there were 7 male infants in whom jaundice was a prominent feature at the height of the illness. Jaundice in these cases was usually associated with anaemia, and a considerable portion of the total bilirubin was present in conjugated form, the urine being dark and positive for bile and the stools pale. The infants were usually severely affected and in some the jaundice proved to be the main sign requiring investigation; in the others it was merely one sign of many in an infant who had a severe general disturbance.

Jaundice and urinary infection have been recognized as associated since the publication of Görter and Lignac (1928) and further reports have confirmed this association (Bernstein and Brown, 1962; Hamilton and SassKortsak, 1963; Arthur and Wilson, 1967; Ng and Rawstron, 1971).

These infants had other features in common: all were males and the illness had usually been present for many days before the diagnosis was established; 3 had a positive blood culture and even though blood cultures were not obtained from 2 infants and were sterile in 2 others, all were ill and the severity of the illness was in keeping with septicaemia in every case.

Major anatomical anomalies. These were absent in the majority. Two infants had major general malformations and associated urinary tract anomalies; 2 infants had Down's syndrome unassociated with urinary tract anomalies; one boy had severe bilateral hydronephrosis not associated with lower urinary tract obstruction (infants with spina bifida were not included in the series).

\section{Investigations}

Bacteriology. 'Coliforms' were the most frequent organisms isolated. Urine specimens from earlier cases were examined by a variety of techniques and detailed analysis of the type of coliform isolated was not undertaken. However, cultures were performed in all cases and before the introduction of quantitative cultures in 1966, urines invariably produced a heavy growth on culture which was associated with gross pyuria (see below).

Furthermore, fresh uncentrifuged urine specimens from 50 of the 66 infants were examined by the author and invariably revealed obvious bacteriuria-a finding that correlates closely with colony counts of more than 100,000 organisms per $\mathrm{ml}$ on culture. That 55 were coliform infections and 4 proteus species is in keeping with other series of acute urinary tract infection. One further infant who has not been included in the present series had a urinary infection by Trichomonas vaginalis and has been reported elsewhere (Littlewood and Kohler, 1966).

Urine white cells. No attempt was made to count white cells before 1964 other than by recording the number visible in each high power microscopic field-usually of the centrifuged deposit. In 47 cases, pus cells, as judged by these methods, were so numerous that such terms as 'pure pus', 'frank pus', 'too numerous to count' were used to describe the findings on microscopy.

Where white cell counts were performed, there were more than 500 per $\mathrm{mm}^{3}$, in 15 cases, in one case between 100-200 per $\mathrm{mm}^{3}$, and in only one case less than 50 cells per $\mathrm{mm}^{3}$, and in this infant the diagnosis was established by culture of a urine specimen obtained by suprapubic aspiration.

When clinical illness is present, it is usually possible to see numerous pus cells on microscopy of even an uncentrifuged specimen. However, during the early days of the infection or in the rare case of bacteruiria without pyuria, it has been our experience that reliance on white cell count alone would lead to occasional errors in diagnosis.

Blood culture. Positive cultures were obtained from 10 of 30 boys (33\%), and from 1 of 7 girls $(14 \%)$, where the investigation was performed.

Proteinuria. This (20 mg/100 $\mathrm{ml}$ or more) was present in only 33 infants $(50 \%)$, absent in 10 , 
and not recorded in 23, re-emphasizing the welldocumented fact that the presence or absence of proteinuria is a totally unreliable test for the presence of urinary tract infection even in this age group.

Haematuria. Microscopical and/or chemical haematuria was present in 24 of 35 infants where information was available.

White blood count. In half the infants leucocytosis of more than 16,000 per $\mathrm{mm}^{3}$ was recorded. In 25 of the infected infants the white count never exceeded 16,000 per $\mathrm{mm}^{3}$.

Blood urea. 35 infants had levels of more than $50 \mathrm{mg} / 100 \mathrm{ml}$ and 11 of these were more than $100 \mathrm{mg} / 100 \mathrm{ml}$; the highest value recorded was 261 $\mathrm{mg} / 100 \mathrm{ml}$ in the absence of renal anomaly. In contrast to older patients, an appreciable degree of nitrogen retention is a frequent occurrence in neonatal urinary tract infection. This finding is not necessarily associated with either renal anomaly or pre-existing renal insufficiency.

Radiological investigations. The quality of intravenous pyelograms in many of the earlier cases in the present series was unsatisfactory as judged by present-day standards and a number of the infants had no radiological investigation (Table III). Until recently a micturating cystogram has not been performed when the intravenous pyelogram revealed no abnormality and only 2 , other than those detailed in Table IV, were done and both were normal.

TABLE III

Intravenous Pyelograms in Present Series

\begin{tabular}{l|c|c|c}
\hline \multicolumn{1}{r|}{ IVP } & Boys & Girls & Total \\
\hline Abnormal & 7 & 2 & 9 \\
Normal & 18 & 8 & 26 \\
Not done & 21 & 10 & 31 \\
Total & 46 & 20 & 66 \\
& & & \\
\hline
\end{tabular}

TABLE IV

Details of Radiological Abnormalities

\begin{tabular}{|c|c|}
\hline Boys & $\begin{array}{l}1 \text { Right cystic kidney; left hydronephrosis } \\
2 \text { Small right kidney with associated right ureteric } \\
\text { reflux on investigation at } 23 \mathrm{mth} \\
3 \text { Bilateral hydronephrosis } \\
4 \text { Bilateral hydronephrosis with ureteric reflux } \\
5 \text { Wide ureters on IVP with bilateral ureteric reflux } \\
6 \text { Fullness of left renal pelvis } \\
7 \text { Fullness of left renal pelvis }\end{array}$ \\
\hline Girls & $\begin{array}{l}1 \text { Slightly dilated left renal pelvis } \\
2 \text { Normal IVP but right ureteric reflux }\end{array}$ \\
\hline
\end{tabular}

In only 3 boys were gross congenital anomalies present: in others the findings were probably caused by, rather than were the cause of, the infection. No gross anatomical anomalies were discovered in the 20 girls. It is of particular interest that there were no infants with bladder neck obstruction due to urethral valves among the 46 boys.

\section{Treatment}

All infants received between 2 and 6 weeks of chemotherapy; many were treated with sulphonamides, and more recently ampicillin was the drug of choice. A number of the severely ill infants were treated with either streptomycin or chloramphenicol. Response to treatment was usually rapid and no relation was evident between recurrence and reinfection and the duration of therapy.

\section{Outcome}

Mortality. 7 infants ( 6 boys and 1 girl) of the 66 died $(11 \%)$. In 2 , death was primarily due to renal anomalies incompatible with prolonged survival. However, in $\mathbf{5}$ the deaths were primarily as a result of pyelonephritis without associated renal anomaly. They were infants in the earlier part of the series, 2 in 1953, 2 in 1959, and 1 in 1964. One had Down's syndrome and therapy had been limited to alkalis alone, the other 4 had received only alkalis and sulphadimidine. 3 of the 5 had positive blood cultures (all coliform species).

Thus, alkalinization of the urine and sulphonamides cannot be regarded as adequate therapy for infants who are clinically ill with pyelonephritis, and no infants in the series have died of primary pyelonephritis in recent years where vigorous antibiotic therapy has been instituted at the time of diagnosis. Even infants in renal failure may undergo complete recovery with the aid of peritoneal dialysis (Meadow et al., 1971).

Recurrence and re-infection. All 58 survivors were followed for at least 3 months, 46 for 6 months or more and 21 for more than 2 years. During this time, the recurrence rate was $19 \%$; this may well be an underestimate. Female infants had a significantly greater recurrence rate (37\%) than males $(10 \%)(0.05>P>0.02)$.

\section{Discussion}

Previously reported series may be conveniently divided into 3 main groups.

(a) Earlier series of small numbers of infants. In the majority the clinical illness was 
severe and the condition regarded as a rarity by the authors (Smith, 1918; Helmholz, 1918; Graham, 1925; Sauer, 1925; Conrad 1926; Paterson, 1931; Florman and Bass, 1943). The series of Craig (1935) was exceptional in that 61 infants were reported; the majority had severe clinical disturbance.

A typical series is that of Sauer (1925), who described 15 newborns with urinary infection. He noted that gastrointestinal symptoms predominated and at times were present for some days before the diagnosis was established. Ashen pallor and anxious facies were commonly observed. $\mathrm{He}$ found that signs in order of frequency were anorexia, diarrhoea, weight loss, tympanites, pallor, anxious facies, vomiting, constipation, cyanosis, and convulsions.

Craig (1935) described a characteristic clinical picture. The onset of the illness was usually indefinite; prolonged anuria, especially when accompanied by fever or occasional vomiting, was suggestive of the start of urinary tract infection, later restlessness, thirst, sweating developed, and colour changes were characteristic of the illness at its height. Collapse occurred occasionally; though high fever was common, a few cases ran an afebrile course. Convulsions, when they occurred, were of grave significance. He noted the association with intracranial disturbance and also the association with severe alimentary disturbance.

These are but 2 examples, nevertheless they do reflect the severe clinical disturbance associated with the condition in the experience of the earlier writers on the subject.

(b) More recent series where the infants had a milder clinical disturbance. (Smellie et al., 1964; James, 1959). Though clinical illness in these infants was milder, they had a deviation from the normal clinical course, i.e. they were not asymptomatic nor detected by deliberate screening. Both contained a preponderance of girls and for this reason the diagnostic criteria employed have been questioned (Braude, Forfar, and Gould, 1964).

Smellie and her colleagues (1964), describing the signs in 45 infants aged less than 1 month with urinary infection as part of a larger study of 200 children, noted that gain in weight was unsatisfactory in all cases, though some had improved by the time the result of the urinary investigation was available. Vomiting was present in 11 cases, diarrhoea in 8, and fever in only 5.

Describing cases of similar type, James (1959) wrote 'the symptoms of urinary infection in the newborn are loss of weight, anorexia, and apathy. Fever and vomiting are occasionally seen'. This is misleading in that conclusions have been drawn from a small series of 32 mild cases. It is incorrect that fever is only occasionally seen in the condition as a whole, for even in mild cases fever is relatively common; furthermore no mention is made of the more severe type of case described by earlier writers, where the urinary infection may be associated septicaemia requiring vigorous and urgent treatment.

(c) Studies where a deliberate search was undertaken to detect urinary infection in the newborn. (Lincoln and Winberg, 1964; O'Doherty, 1968; Littlewood et al., 1969). Clinically these infants have been either asymptomatic or only mildly ill at the time of diagnosis. They frequently undergo spontaneous recovery without ever having significant clinical signs. The 9 cases of Lincoln and Winberg (1964) and the 8 cases

TABLE V

Mortality Rate and Recurrent Rate

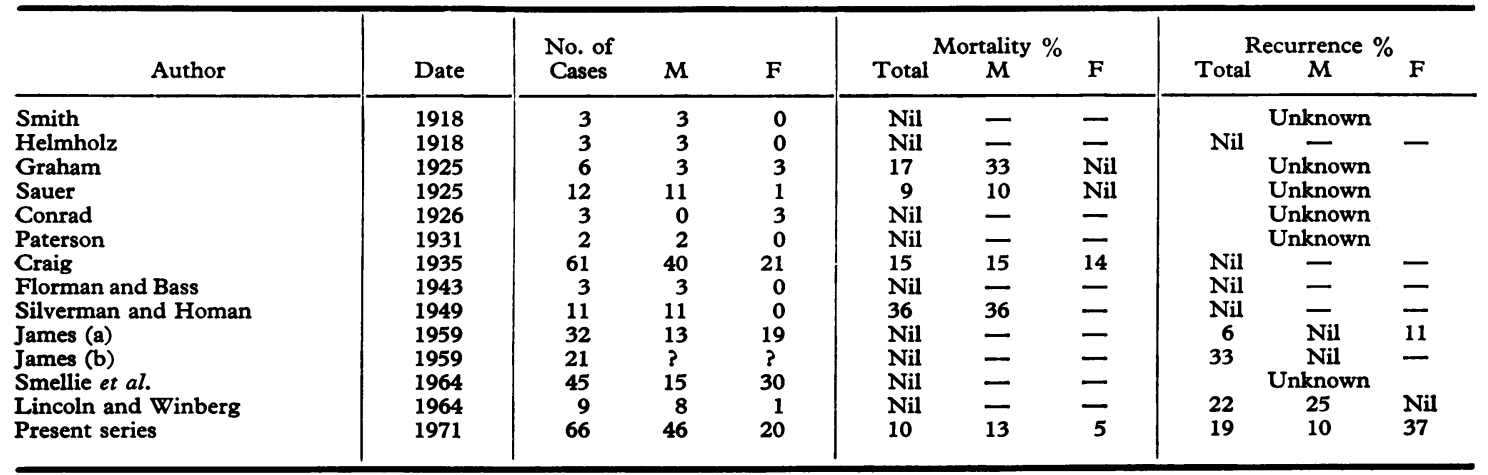


detected during the author's recent survey (Littlewood et al., 1969) were of this type. If one were to draw conclusions as to the clinical manifestations of urinary infection in the newborn from any one of the above reports, a misleading impression would be obtained.

It is suggested that the condition in the newborn infant has a wide spectrum of clinical manifestations ranging from an infant with overwhelming septicaemia associated with pyelonephritis, to an asymptomatic infant who nevertheless has unequivocal evidence of infection within the urinary tract as judged by urine examination-if necessary obtained by suprapubic aspiration.

After consideration of the previously reported cases and also the 66 infants of the present series, it is suggested that infants may be grouped as follows. (1) Infants with clinical picture of pyelonephritis and general disturbance compatible with septicaemic illness (17 cases). (2) Infants with known congenital anomalies of the urinary tract and associated secondary infection, e.g. spina bifida, bladder neck obstruction, gross renal anomalies ( 2 cases). (3) Infants with mild but definite clinical disturbance usually limited to anorexia, lethargy, and failure to gain weight (39 cases). (4) Infants with few, if any, signs where the infection is discovered as an incidental finding or during a screening survey designed to detect such cases ( 8 cases).

Though asymptomatic infants may develop clinical signs and the age of detection may determine into which group the infant is first classified, the infants in these 4 categories present different clinical problems, particularly with regard to prognosis and the urgency with which treatment is required. The writer believes that infants in group (4) more often than not undergo spontaneous recovery and remain unrecognized in the majority of maternity units. However, they represent an 'at risk' group from which infants developing clinical illness arise.

It is only when the wide variation in clinical manifestations of the disease is appreciated that any useful conclusions can be drawn as to the incidence, clinical manifestations, and prognosis.

A number of other features peculiar to the newborn with urinary infection are worthy of comment. It has been stated that the male preponderance in neonatal urinary tract infection is entirely accounted for by the presence of anatomical abnormalities (Hutchison, 1965). This statement is not borne out by the experience of those who have extensively investigated newborns with urinary infection (Smellie et al., 1964) or by the writer. In the present series only a minority of newborns with such infections have gross anatomical abnormalities. If micturating cystograms are also performed, about half the infants are found to have radiological abnormalities (as opposed to 'gross anatomical') (J. M. Smellie, personal communication, 1966) and these abnormalities commonly take the form of ureteric reflux. The presence of vesicoureteric reflux is regarded as abnormal even in this age group (Lich, Howerton, and Davis, 1965).

Though radiological investigation was performed infrequently in the earlier cases of the present series, it is probable that if gross anatomical abnormalities had been present, frequent relapses of the infection would have occurred and this has not been our experience. In only 3 boys, of the 27 where information was available, were gross congenital anomalies of the urinary tract present. When the 8 asymptomatic cases are considered, not one of the boys had a significant anatomical lesion which would have accounted for the development of urinary infection. It is suggested that the frequency with which gross anatomical abnormalities occur in association with urinary tract infection in this age group, and in which they are a major factor in the aetiology, has been overestimated in the past.

The male preponderance of cases in most series of urinary infection at this age is considered to be related to the mode of infection, thought to be usually blood borne. Transient bacteraemia in the first days of life is believed to be a not uncommon occurrence during initial bacterial colonization of the infant (Albers, Tyler, and Boxerbaum, 1966), and renal tissue is particularly susceptible to bacterial infection. Newborn male infants are more commonly affected by bacteraemic illness than are females, and consequently by urinary infection. If the route of infection were ascending the strong female preponderance found in older children would be expected.

With regard to the local susceptibility of the kidney to bacterial infection, there is evidence that local tissue changes in the kidney may follow anoxia in the perinatal period. Many authors produced evidence that renal damage was not uncommon in these circumstances (McCance and Widdowson, 1954; Kessel and Pepler, 1955; Bernstein, 1958; Jonsson, 1961; Halvorsen and Aas, 1962; Tan and Hull, 1969). Urinalysis in such cases frequently reveals increased numbers of renal epithelial cells and casts. It is perhaps relevant that renal epithelial cells are more commonly found in greater numbers in the urine of male than female infants. It is possible that anoxic damage in the 
kidney renders that organ more susceptible to bacterial invasion and colonization during transient episodes of bacteraemia and is of importance in the genesis of neonatal pyelonephritis. The increased incidence of perinatal anoxia in the present series lends support to this suggestion.

The weight distribution in the present series is of interest and has not been recorded previously. It would not be an unexpected finding if infected infants were frequently premature or postmature, though in the present series the numbers did not reach statistical significance. Postmaturity has been noted to be associated with an increase in the cellular elements in the urine suggesting renal tissue damage (Halvorsen and Aas, 1962). Prematurity is commonly held to be associated with a higher incidence of infection of all types; one aspect of this susceptibility has recently been quantitated in terms of immunoglobulin levels, IgG levels showing a close correlation with the degree of immaturity (Hobbs and Davis, 1967).

Unless urinary examination is performed as a routine investigation in all newborn infants where the clinical course deviates in any way from the normal, particularly with respect to feeding difficulties, anorexia, failure to gain weight, or pyrexia, the majority of newborns with this infection will continue to go undetected. It is, therefore, perhaps fortunate for the majority that they appear to recover without treatment, but unfortunate for the minority who progress within days or weeks to the severe type of illness with possible early death; some of these deaths are from acute reversible renal failure and the use of peritoneal dialysis will now return such infants to normal health (Meadow et al., 1971). Others will develop chronic renal infection with subsequent scarring (Lincoln and Winberg, 1964). It is for the sake of these minority groups that the condition should be excluded in all infants with even mild deviation from the normal clinical course in the first weeks of life.

The author thanks Professor W. S. Craig for advice and encouragement, Dr. Roy Meadow for helpful criticism, and Mrs. Anne Brightwell for secretarial assistance.

\section{REFERENCES}

Albers, W. H., Tyler, C. W., and Boxerbaum, B. (1966). Asymptomatic bacteremia in the newborn infant. Fournal of Pediatrics, 69, 193.

Arthur, A. B., and Wilson, B. D. R. (1967). Urinary infection presenting with jaundice. British Medical fournal, 1, 539.

Bernstein, J. (1958). Renal tubular and pancreatic islet necrosis in newly born infants. American fournal of Diseases of Children, 96, 705.

Bernstein, J., and Brown, A. K. (1962). Sepsis and jaundice in early infancy. Pediatrics, 29, 873.
Braude, H., Forfar, J. O., and Gould, J. C. (1964). Urinary infection in childhood. British Medical fournal, 2, 1393.

Burke, J. B. (1961). Pyelonephritis in infancy and childhood. Lancet, 2, 1116.

Butler, N. R., and Bonham, D. G. (1963). Perinatal Mortality: The First Report of the 1958 British Perinatal Mortality Survey. Livingstone, Edinburgh.

Conrad, C. E. (1926). Congenitally acquired pyelitis. American Fournal of Diseases of Children, 31, 253.

Craig, W. S. (1935). Urinary disorders occurring in the neonatal period. Archives of Disease in Childhood, 10, 337.

Craig, W. S. (1961). Vomiting in the early days of life. Archives of Disease in Childhood, 36, 451.

Craig, W. S. (1963). Early detection of pyrexia in the newborn. Archives of Disease in Childhood, 38, 29.

Davis, L. A., and Chumley, W. F. (1966). The frequency of vaginal reflux during micturition: its possible importance to the interpretation of urine cultures. Pediatrics, 38, 293.

Florman, A., and Bass, M. H. (1943). Pyuria of the newborn treated with sulfathiazole. Fournal of the American Medical Association, 122, 656.

Görter, E., and Lignac, G. O. E. (1928). On pyelitis complicated by jaundice. Archives of Disease in Childhood, 3, 232.

Graham, R. H. (1925). A report of six cases of pyelitis in the newlyborn infant. American fournal of the Medical Sciences, 170, 401.

Halvorsen, S., and Aas, K. (1962). Observations on the urine of asphyxiated and dysmature newborn infants. Acta Paediatrica, $51,417$.

Hamilton, J. R., and Sass-Kortsak, A. (1963). Jaundice associated with severe bacterial infection in young infants. Fournal of Pediatrics, 63, 121.

Helmholz, H. F. (1918). Pyelitis in the newborn. Medical Clinics of North America, 1, 1451.

Hobbs, J. R., and Davis, J. A. (1967). Serum $\alpha$ G-globulin levels and gestational age in premature babies. Lancet, $1,757$.

Hutchison, J. H. (1965). Acute infections of the urinary tract in childhood. Practitioner, 194, 338.

James, U. (1959). Urinary infection in the newborn. Lancet, 2, 1001 .

Jonsson, B. (1961). Lower nephron nephrosis in asphyxia neonatorum. Acta Paediatrica, 40, 401

Kessel, I., and Pepler, W. J. (1955). Lower nephron nephrosis in the newborn. Fournal of Obstetrics and Gynaecology of the British Empire, 62, 98.

Lich, R., Jr., Howerton, L. W., and Davis, L. A. (1965̄). Ureteral reflux and the vesical neck of the normal newborn. In Progress in Pyelonephritis, p. 645 . Ed. by E. H. Kass. Davis, Philadelphia.

Lincoln, K., and Winberg, J. (1964). Studies of urinary tract infections of infancy and childhood. II. Quantitative estimation of bacteriuria in unselected neonates with special reference to the occurrence of asymptomatic infections. Acta Paediatrica, $53,307$.

Littlewood, J. M., Kite, P., and Kite, B. A. (1969). Incidence of neonatal urinary tract infection. Archives of Disease in Childhood, 44, 617.

Littlewood, J. M., and Kohler, H. G. (1966). Urinary tract infection by Trichomonas vaginalis in a newborn baby. Archives of Disease in Childhood, 41, 693.

McCance, R. A., and Widdowson, E. M. (1954). The influence of events during the last few days in utero on tissue destruction and renal function in the first two days of independent life. Archives of Disease in Childhood, 29, 495.

Meadow, S. R., Cameron, J. S., Ogg, C. S., and Saxton, H. M. (1971). Children referred for acute dialysis. Archives of Disease in Childhood, 46, 221.

$\mathrm{Ng}, \mathrm{S}$. H., and Rawstron, J. R. (1971). Urinary tract infections presenting with jaundice. Archives of Disease in Childhood, 46, 173.

O'Doherty, N. (1968). Urinary tract infection in the neonatal period and later infancy. In Urinary Tract Infection, p. 113. Ed. by F. O'Grady and W. Brumfitt. Oxford University Press, London.

Paterson, D. (1931). Pyelitis in newly born infants. Lancet, 2, 1186.

Sauer, L. W. (1925). Neonatal pyelitis. Fournal of the American Medical Association, 85, 327. 
Silverman, W. A., and Homan, W. E. (1949). Sepsis of obscure origin in the newborn. Pediatrics, $3,157$.

Smellie, J. M., Hodson, C. J., Edwards, D., and Norman, I. C. S. (1964). Clinical and radiological features of urinary infection in childhood. British Medical fournal, 2, 1222.

Smith, R. M. (1918). Pyelitis of infancy. Medical Clinics of North America, 1, 1165 .

Stansfeld, J. M. (1966). Clinical observations relating to incidence and aetiology of urinary-tract infections in children. British Medical fournal, 1, 631.
Tan, K., and Hull, D. (1969). The excretion of cells in urine $\frac{\rho}{-}$ following perinatal asphyxia. Pediatric Research, 3, 228.

Wharton, L. R., Gray, L. A., and Guild, H. G. (1937). The late. effects of acute pyelitis in girls. Fournal of the American $\Rightarrow$ Medical Association, 109, 1597.

Correspondence to Dr. J. M. Littlewood, Seacroft $\frac{\bar{O}}{\bar{c}}$ Hospital, York Road, Leeds LS14 6UH.

The following articles will appear in future issues of this journal:

Calcifications of the Carotid Siphon-A Common Finding in Infancy and Childhood. By W. W. Meyer and J. Lind.

Clinical and Social Status of Patients with Congenital Rubella. By S. M. Gumpel.

Deaths from Acute Lead Poisoning. By F. W. Alexander and H. T. Delves.

Polymorphonuclear Leucocytic Count in Diagnosis of Infection in the Newborn. By S. A. Haider.

Annotation: House Dust Mites and Allergy. By A. W. Frankland.

Intestinal Absorption of Immunoglobulins by Newborn Infants. By L. Iyengar and R. J. Selvaraj.

Generalized Bronchiectasis Due to Extensive Deficiency of Bronchial Cartilage. By H. E. Williams,

L. I. Landau, and P. D. Phelan.

Personal Practice: Management of the Haemophilic Child. By C. R. Rizza and J. M. Matthews.

Treatment of Pneumothorax in the Newborn Infant. By A. Ramachandra and G. Russell.

Cytomegalovirus Infection as Acute Haemolytic Anaemia in an Infant. By A. J. Franklin.

Oral Manifestations of Letterer-Siwe Disease. By P. R. Betts and A. S. McNeish.

Diencephalic Syndrome of Infantile Emaciation. Analysis of Literature and Report of a Further 3 Cases. By D. P. Addy and F. P. Hudson.

Premature Rupture of Membranes and Effects of Prophylactic Antibodies. By A. H. Habel, G. S. Sandor, N. K. Conn, and W. M. McCrae. 